\title{
Spatial distribution of net surface accumulation on the Antarctic ice sheet
}

\author{
M. B. Giovinetto, ${ }^{1}$ H. J. Zwally ${ }^{2}$ \\ ${ }^{1}$ Raytheon ITSS, NASA Goddard Space Flight Center, Code 971, Greenbelt, MD 20771, U.S.A. \\ ${ }^{2}$ NASA Goddard Space Flight Center, Code 971, Greenbelt, MD 20771, U.S.A.
}

\begin{abstract}
An isopleth map showing the spatial distribution of net mass accumulation at the surface on the Antarctic ice sheet, excluding Graham Land, the Larsen Ice Shelf and eastern Palmer Land, is produced based on field data from approximately 2000 sites. A database of accumulation values for 5365 gridpoint locations with $50 \mathrm{~km}$ spacing is interpolated from the isopleth map, giving a bulk accumulation of $2151 \mathrm{Gt} \mathrm{a}^{-1}$ and a mean of $159 \mathrm{~kg} \mathrm{~m}^{-2} \mathrm{a}^{-1}$ for an area of $13.53 \times 10^{6} \mathrm{~km}^{2}$. Following the implementation of deflation and ablation adjustments applicable to sectors of the coastal zone, the accumulation values are reduced to $2020 \mathrm{Gt} \mathrm{a}^{-1}$ and $149 \mathrm{~kg} \mathrm{~m}^{-2} \mathrm{a}^{-1}$. The new accumulation distribution is compared with another recent distribution, which was based on essentially the same field data using different analysis and interpolation criteria. Differences between the distributions are assessed using residuals for the $50 \mathrm{~km}$ gridpoint locations and by comparing average accumulation values for 24 drainage systems. The assessment based on residuals indicates that the two distributions show patterns of accumulation that are coherent at the continental scale, a shared attribute underscored by a small mean residual value of $6 \mathrm{~kg} \mathrm{~m}^{-2} \mathrm{a}^{-1}$ (a difference of $<4 \%$ ). However, the regional assessment based on average accumulation values for the drainage systems shows differences that are larger than the assessment error $(\geq 22 \%)$ for six systems that collectively comprise approximately $4 / 10$ of the ice-sheet area and 3/10 of the accumulation.
\end{abstract}

\section{INTRODUCTION}

Recent literature shows the importance of glaciological and climatological research on Antarctica in studies of global change (e.g. Ohmura and others, 1996a; Budd and others, 1998) that depend to a large extent on reliable information on mean annual net surface accumulation or surface balance to complement findings involving glaciological (e.g. Bentley and Giovinetto, 1991; Jacobs and others, 1992; Budd and Warner, 1996), atmospheric (e.g. Genthon and Braun, 1995; Ohmura and others, 1996b; Bromwich and others, 1998) and other geophysical phenomena (e.g. Conrad and Hager, 1995; James and Ivins, 1997; Bentley and Wahr, 1998). In this study we present a new distribution of accumulation, excluding the area of Graham Land, Larsen Ice Shelf and eastern Palmer Land represented by drainage systems (25-27) (Fig. 1).

We estimate the mean rate of accumulation based on the new distribution, and compare it with the results obtained from the latest distribution prepared by Vaughan and others (1999) using practically the same field data but different interpolation criteria. A first, direct comparison between our distribution and that of Vaughan and others (1999) is made using a field of residuals described in a $50 \mathrm{~km}$ grid format. A second, indirect comparison between our distribution and that of Vaughan and others (1999) is made by comparing estimates of accumulation for 24 drainage systems (systems 9-11 treated as one) relative to a third compilation (Giovinetto and Bentley, 1985). Vaughan and others (1999) compared their estimates of mean accumulation for the grounded-ice area of each system as estimated by Giovinetto and Bentley (1985), and we make a similar analysis for our distribution. The direct and indirect comparisons show the extent to which our distribution and that of Vaughan and others (1999) are largely coherent at the continental scale, but differ at the regional scale. Regional accumulation estimates are important in studies such as mass budget of particular systems (e.g. Bentley and Giovinetto, 1991; Pattyn, 1996; Rignot, 1998) and validation of model output derived from atmospheric numerical analyses (e.g. Genthon and Braun, 1995; Ohmura and others, 1996b; Bromwich and others, 1998).

\section{ACGUMULATION AT THE SURFAGE}

\section{Field-data compilation update}

We expand a previous compilation of field data from approximately 1500 sites (Giovinetto and Bentley, 1985; Giovinetto and Bull, 1987) by adding data from approximately 500 sites (Whillans and Bindschadler, 1988; Goodwin, 1990; Jenkins and Doake, 1991; Morgan and others, 1991; Goodwin and others, 1994; Graf and others, 1994; Isaksson and Karlén, 1994; Mosley-Thompson and others, 1995; Higham and others, 1997; Richardson and others, 1997; Takahashi and Watanabe, 1997; Casassa and others, 1998; Melvold and others, 1998; Venteris and Whillans, 1998; Van den Broeke and others, 1999; personal communication from A. R. Ruddell, 1999). The latest comprehensive distribution of field-data sites is shown in Vaughan and others (1999) based on a compilation of 1860 sites for the area of all 27 drainage systems. Overall, the field data are representative of mean accumulation values determined for periods of lyear to several decades from observations on strata accumulated approximately between 1940 and 1995. Therefore, spatial and temporal variations at 


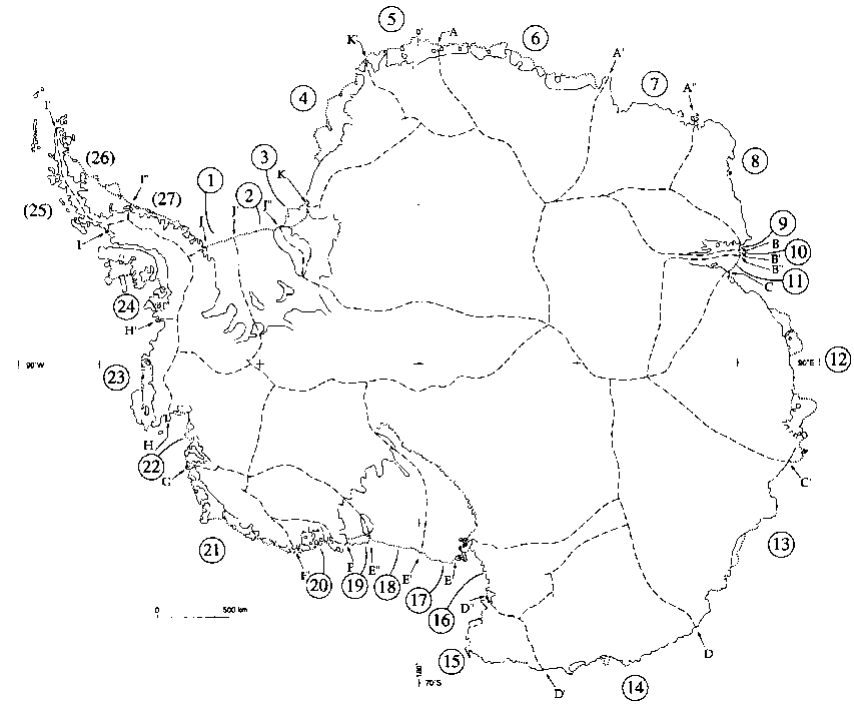

Fig. 1. Antarctica, showing a delineation of drainage divides (Giovinetto and Bentley, 1985) and drainage-system designation. The area of systems (25-27) is not included in this study, and systems $9-11$ are treated as one. Sector $7-K$ and $E-F$ correspond to the Filchner-Ronne and Ross Ice Shelves, respectively.

local and regional scales should be noted (e.g. Morgan and others, 1991; Mosley-Thompson and others, 1995). We produce an isopleth pattern based on visual interpolation of field data (Fig. 2). Our criteria for drawing isopleths based on visual interpolation are described elsewhere (Giovinetto and Bentley, 1985; Giovinetto and others, 1990). In two areas we copied the visually interpolated isopleth pattern shown in the source pub- lications rather than contour the data ourselves; we blended the pattern drawn by Takahashi and Watanabe (1997) for the sector $20-50^{\circ} \mathrm{E}$, north of $75^{\circ} \mathrm{S}$, and by Higham and others (1997) and A. R. Ruddell (personal communication, 1999) for the Amery Ice Shelf drainage system (systems 9-11).

\section{Methodology and interpretative aspects}

As an aid to the interpretation of the distribution shown in Figure 2, we comment on three aspects that are relevant to the results discussed later in this paper. The first aspect is the contrast between visual interpolation of field data to produce an isopleth pattern and thus describe a distribution, and interpolation of field data using computer-based approaches. Despite quantification of bivariate and multivariate relationships where accumulation is the dependent variable (e.g. Chorlton and Lister, 1970; Giovinetto and others, 1990), visual interpolation is largely subjective (e.g. Giovinetto and Bentley, 1985; Higham and others, 1997; Takahashi and Watanabe, 1997). Interpolation using computer-based approaches is reliable, particularly in the sense that subjectivity is reduced (e.g. Vaughan and others, 1999), but so is sensitivity to regional differences (e.g. differences in tropospheric circulation and surface air flow which affect water-vapor advection and blowingsnow transport, respectively). Nevertheless, interpolation by any known method is unreliable for areas characterized by sparse data or physiographic complexity, such as relatively narrow zones adjacent to segments of coast, grounded or floating ice terminus, and grounding lines, as well as mountain regions.

The second aspect is the treatment of field data for approximately 60 sites (Giovinetto and others, 1989) that, relative to the cumulative total of approximately 2000 sites, represent $3 \%$ of the whole dataset and $<10 \%$ of data

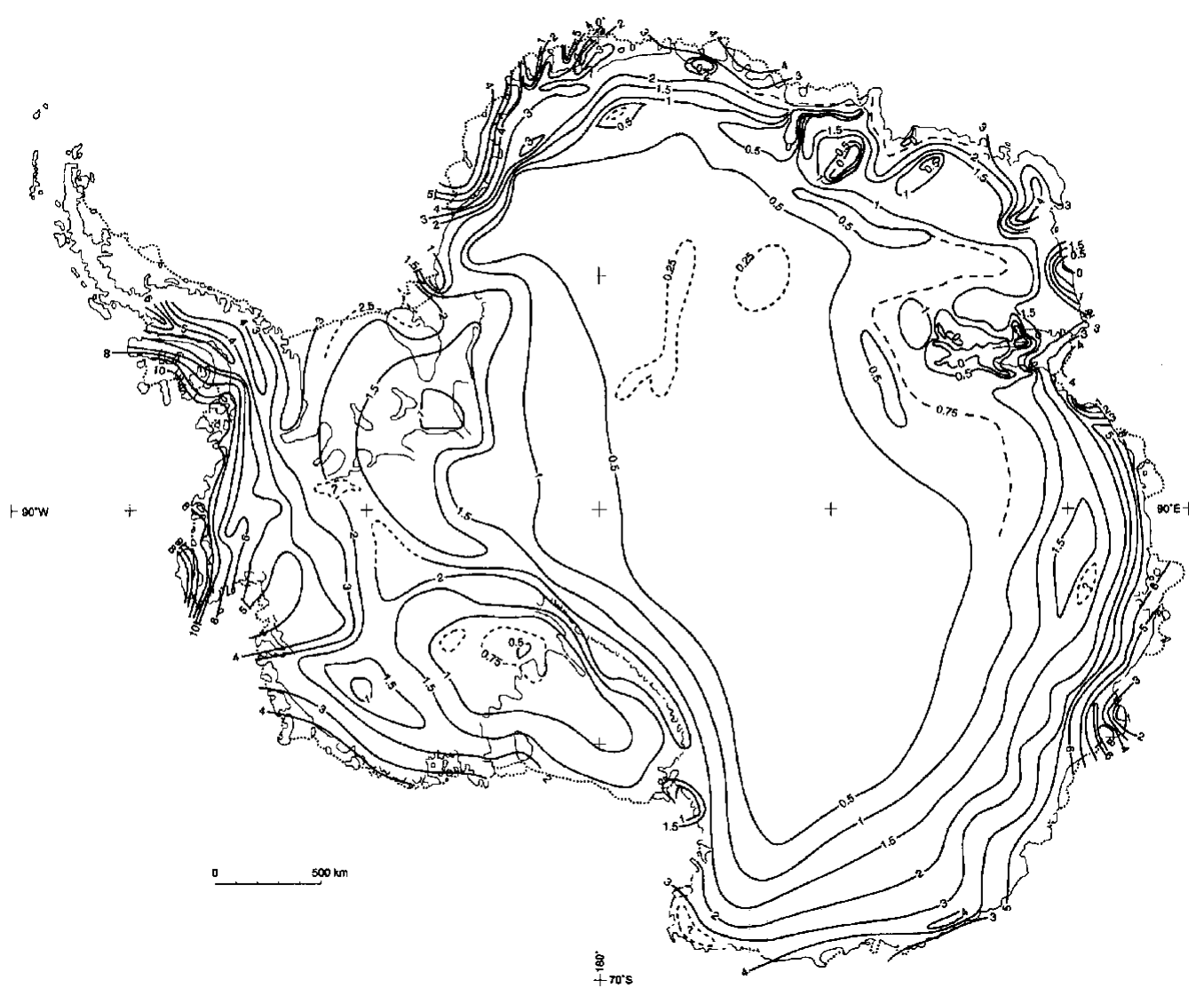

Fig. 2. Antarctica, showing the distribution of net accumulation at the surface (isopleths labeled in $100 \mathrm{~kg} \mathrm{~m}^{-2} a^{-1}$ ). The isopleth pattern is visually interpolated on the basis of approximately 2000 field-data sites. 
a

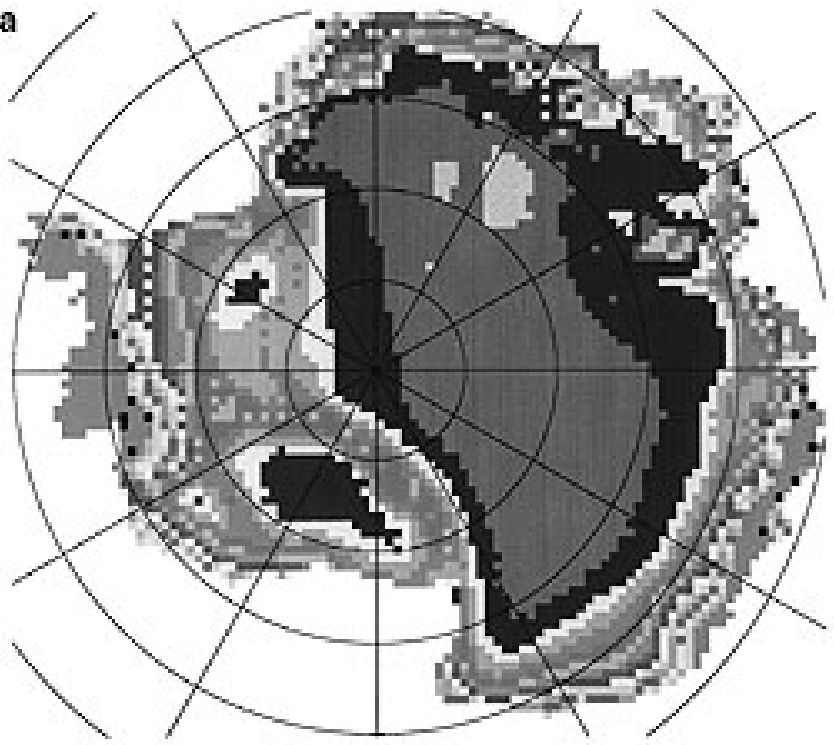

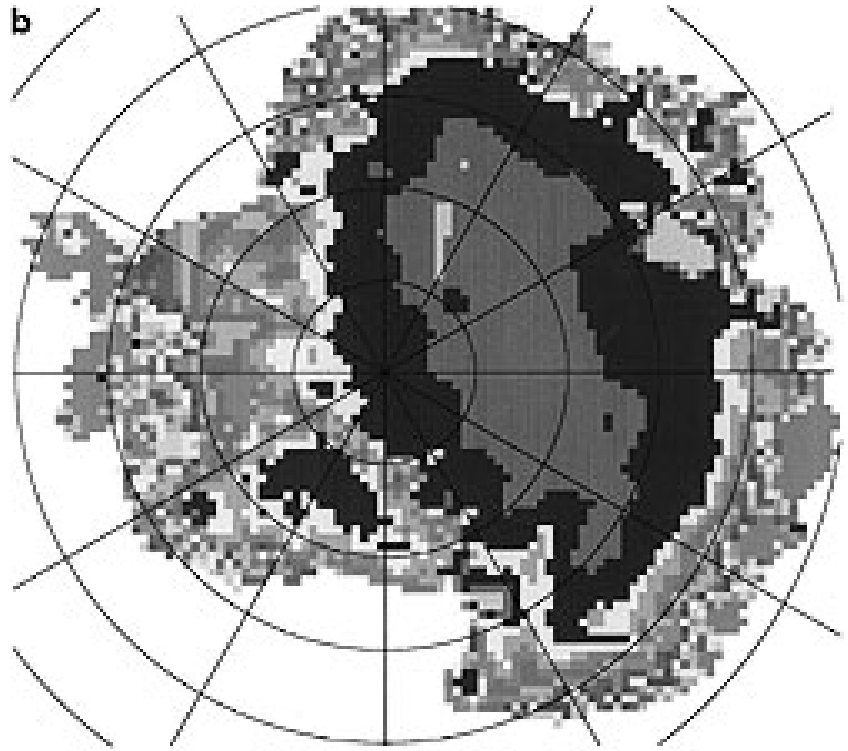
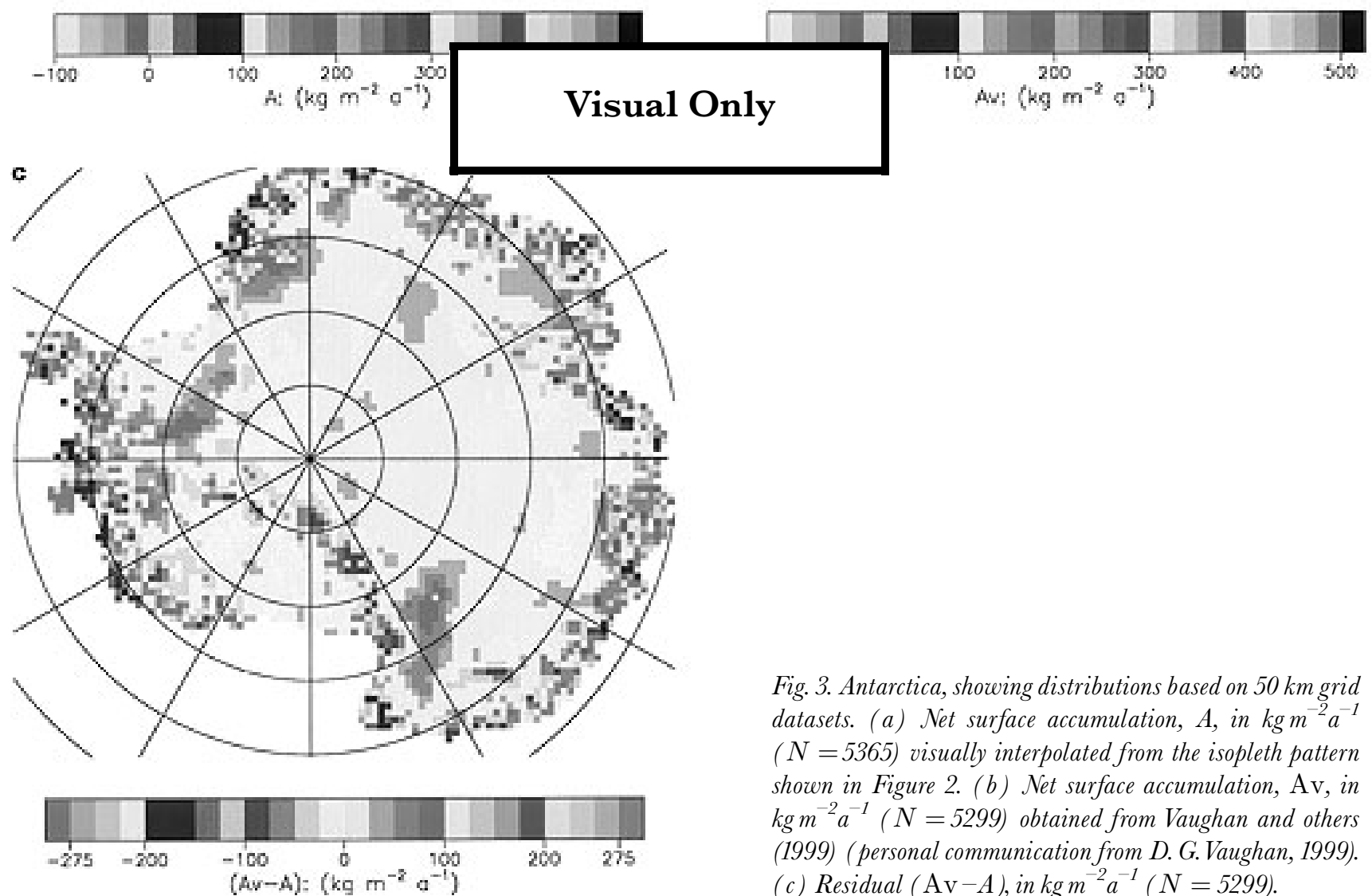

Fig. 3. Antarctica, showing distributions based on $50 \mathrm{~km}$ grid datasets. (a) Net surface accumulation, $A$, in $\mathrm{kg} \mathrm{m}^{-2} a^{-1}$ ( $N=5365)$ visually interpolated from the isopleth pattern shown in Figure 2. (b) Net surface accumulation, Av, in $\mathrm{kg} \mathrm{m}^{-2} \mathrm{a}^{-1}(N=5299)$ obtained from Vaughan and others (1999) (personal communication from D. G.Vaughan, 1999). (c) Residual ( $\mathrm{Av}-A)$, in $\mathrm{kg} \mathrm{m}^{-2} a^{-1}(N=5299)$.

obtained using the so-called stratigraphic method. The data for the approximately 60 sites are not considered in the drawing of isopleths, because they are incompatible with other datasets produced using different methods for the same areas. This exclusion of data from the interpolation process involves datasets in which multi-year mean accumulation values were determined using the stratigraphic method exclusively, as opposed to determinations based on other methods such as stable isotopes, gross beta activity and stake measurements, or combinations of any of these including the stratigraphic method. In the areas where the accumulation values determined using the stratigraphic method alone were subsequently shown to be different from values determined by other methods, the stratigraphic method generally produced values that were larger by a factor of 2 (i.e. the difference is much larger than any expected

temporal variability of multi-year mean values). Examples of areas for which newer reliable accumulation data have become available are the central and western sectors of the Filchner-Ronne Ice Shelf (Jenkins and Doake, 1991; Graf and others, 1994), and the area centered along approximately $135^{\circ} \mathrm{W}$ between $81^{\circ}$ and $84^{\circ} \mathrm{S}$ (Whillans and Bindschadler, 1988; Venteris and Whillans, 1998). In other areas the uncertainties presented by incompatible datasets remain an issue (e.g. the areas centered approximately at $78^{\circ} \mathrm{S}, 103^{\circ} \mathrm{W}$ and $78^{\circ} \mathrm{S}, 140^{\circ} \mathrm{E}$; these are discussed in a following section).

The third aspect is the implementation of "deflation" and "ablation" adjustments estimated for the coastal zones that are applied to bulk net accumulation estimates (in $\mathrm{Gt} \mathrm{a}^{-1}$ ) for the whole area of the ice sheet or parts thereof, such as drainage systems (Giovinetto, 1964b). The deflation adjustment includes 
the mass loss due to snow removal by wind and sublimation. The ablation adjustment includes the mass loss due to runoff and evaporation. By definition, net accumulation includes these loss terms, but the accumulation isopleth drawn for the coastal zone in small-scale maps cannot show the relatively small (of the order of $10 \mathrm{~km}^{2}$ or less) but widespread deflation and ablation patches. A summary of the observed sporadic area and time distributions of the patches is found elsewhere (e.g. Giovinetto, 1964a, b). The affected sectors of the coastal zone are characterized by surface slope gradient $\geq 1 \%$ and elevation $\leq 1000 \mathrm{~m}$, extending inland from grounded ice termini to $50-100 \mathrm{~km}$ in the case of deflation patches, and to $10-20 \mathrm{~km}$ in the case of ablation patches. Areas with those characteristics also extend inland from grounding lines in some sectors. As the adjustments are estimated independently of the area integration of the accumulation rate, the adjustments do not modify the distribution as shown on a map. Therefore the adjustments should not be implemented in a comparison of distributions. However, the implementation must be included in a comparison of estimates of bulk and mean accumulation values.

In the estimate of accumulation that follows, we implement the adjustments as listed in a preceding study (Giovinetto and Bentley, 1985). The deflation adjustment $\left(117 \mathrm{Gt} \mathrm{a}^{-1}\right)$ is based on half the area of each sector times the rate of accumulation indicated by the isopleth pattern shown for the sector. It should be considered an upper-limit estimate of the mass reductionbecause the literature on which the estimate criteria are based (Giovinetto, 1964a, b) would also support assumptions based on half the area and half the indicated accumulation rate, thus reducing the estimate to approximately $59 \mathrm{Gt} \mathrm{a}^{-1}$. The ablation adjustment $\left(14 \mathrm{Gt} \mathrm{a}^{-1}\right)$ is based on half the area of each sector times the rate of accumulation indicated by the isopleth pattern shown for the sector. All sectors to which the ablation adjustment applies are already included in sectors to which the deflation adjustment applies. Therefore, the combined adjustments bring the accumulation rate to zero (i.e. no net mass loss). In this context, the ablationadjustment should be considered a lower-limit estimate, and larger estimates could be made (e.g. $28 \mathrm{Gt} \mathrm{a}^{-1}$ ). However, because of the sparsity of deflation- and ablation-rate measurements, more definitive estimates do not seem to be justified. As implemented by us, the combined adjustments $\left(131 \mathrm{Gt} \mathrm{a}^{-1}\right)$ are equivalent to a reduction of the mean accumulation over the ice sheet of approximately $10 \mathrm{~kg} \mathrm{~m}^{-2} \mathrm{a}^{-1}$. Implementation of the deflation and ablation adjustments produces some of the lowest estimates of accumulation available in the literature (the latest survey of accumulation estimates is summarized inVaughan and others (1999)). Differences in criteria used in the contouring of field data, or exclusion of parts of them, are less significant. The

\section{Table 1. Summary of accumulation data and estimates}

\begin{tabular}{lrrrrrr} 
Variable & $\begin{array}{c}\text { Grid } \\
\mathrm{N}\end{array}$ & $\begin{array}{c}\text { Mean } \\
\mathrm{kg} \mathrm{m}^{-2} \mathrm{a}^{-1}\end{array}$ & $\begin{array}{c}\text { SD m } \\
\mathrm{kg} \mathrm{a}^{-2} \mathrm{a}^{-1}\end{array}$ & $\begin{array}{c}\text { Min. } \\
\mathrm{kg} \mathrm{m}^{-2} \mathrm{a}^{-1}\end{array}$ & $\begin{array}{c}\text { Max. } \\
\mathrm{kg} \mathrm{m}^{-2} \mathrm{a}^{-1}\end{array}$ & $\begin{array}{c}\text { Bulk } \\
\mathrm{Gt} \mathrm{a}^{-1}\end{array}$ \\
\hline$A$ & 5365 & 159 & 158 & -50 & 1050 & $2151^{\dagger}$ \\
$A$ & $\mathrm{~N} / \mathrm{A}$ & 149 & $\mathrm{~N} / \mathrm{A}$ & $\mathrm{N} / \mathrm{A}$ & $\mathrm{N} / \mathrm{A}$ & $2020^{\ddagger}$ \\
$A$ & 5299 & 155 & 156 & -50 & 1050 & - \\
$\mathrm{Av}$ & 5299 & 161 & 154 & 0 & 1141 & - \\
$(\mathrm{Av}-$ A) & 5299 & 6 & 70 & -493 & 716 & - \\
\hline
\end{tabular}

${ }^{\dagger}$ For an area of $1353 \times 10^{6} \mathrm{~km}^{2}$.

$\ddagger$ After implementation of deflation and ablation adjustments. adjustments are listed for each drainage system (Giovinetto and Bentley, 1985) and therefore can be alternately modified or ignored by simple tabulation. Detailed information on surface topography, mass- and energy-exchange processes, katabatic flow and surface temperature and melting could be combined to improve the criteria and redefine the sectors (e.g. Kobayashi, 1978; Parish and Bromwich, 1991; Comiso, 1994, 2000; Zwally and Fiegles, 1994; Van den Broeke and Bintanja, 1995; Williams and others, 1995; Van den Broeke and others, 1997).

\section{Estimates of bulk and mean accumulation}

The isopleth pattern shown in Figure 2 is sampled in a $50 \mathrm{~km}$ grid (Fig. 3a) to estimate accumulation based on the new distribution. The gridpoint locations correspond to intersections between gridlines parallel to meridians $90^{\circ} \mathrm{W}$ to $90^{\circ} \mathrm{E}$ and gridcolumns parallel to meridians $0-180^{\circ}$ on a polar stereographic projection map with standard line at $71^{\circ} \mathrm{S}$. The accumulation value for each gridpoint location $\left(A\right.$, in $\left.\mathrm{kg} \mathrm{m}^{-2} \mathrm{a}^{-1}\right)$ is obtained by visual interpolation from the isopleth pattern. The grid dataset $(N=5365$, where $N$ is the number of gridpoints) includes ice-shelf areas known to have calved; this is to maintain coherence in data representation because important field data would otherwise appear to correspond to open-ocean areas (e.g. in the northeast regions of the Filchner-Ronne and Ross Ice Shelves (e.g. Ferrigno and others, 1996)). The grid dataset is assembled without information as to whether a peripheral gridpoint should be allocated all of the nominal area of a grid square (i.e. the area of a square centered on each gridpoint location is $2500 \mathrm{~km}^{2}$ ), or more or part of one, depending on the point location relative to the coastline. This omission does not introduce a significant difference in the measurement of area as well as in the integration of accumulation, because the actual under- and overestimates involving peripheral gridpoints are assumed to balance out. However, the database includes the area scale factor derived for each gridpoint square corresponding to the polar stereographic projection with standard line at a latitude of $71^{\circ}$ (derived from Pinther, 1975). The use of the area scale factor allows an approximation to the result that would be obtained using an equal area projection. The dimension of the factor applicable to the $50 \mathrm{~km}$ grid ranges from 0.951 to 1.041 , with a mean value of 1.009 ; the total area is $13.53 \times 10^{6} \mathrm{~km}^{2}$ (Fig. 3a; Table 1). The estimate of net accumulation for this area is $2151 \mathrm{Gta}^{-1}$ for a mean of $159 \mathrm{~kg} \mathrm{~m}^{-2} \mathrm{a}^{-1}$; following the implementation of deflation and ablation adjustments described above, these values are reduced to $2020 \mathrm{Gt} \mathrm{a}^{-1}$ and $149 \mathrm{~kg} \mathrm{~m}^{-2} \mathrm{a}^{-1}$. These unadjusted and adjusted estimates are considered to be preliminary because coarse-grid sampling is not as sensitive as detailed area integration of the rate. The composite error in estimates based on detailed integration has been assessed between $\pm 5 \%$ (Vaughan and others, 1999) and $\pm 10 \%$ (Giovinetto and Bentley, 1985); coarse-grid sampling increases the error by a few percentile (an example is described in a following section).

\section{COMPARISON OF RESULTS}

We compare the distribution of net accumulation shown in Figure 2 with that presented in a previous compilation based on practically the same field data but different criteria of interpolation (Vaughan and others, 1999). For this purpose we were provided with data for the same set of gridpoint 
locations (Av, in $\mathrm{kg} \mathrm{m}^{-2} \mathrm{a}^{-1}$ ) (personal communication from D. G. Vaughan, 1999) (Fig. 3b). The number of gridpoint locations for which Av data $(N=5299)$ could be paired to $A$ data is smaller because the compilations are produced using different base maps (i.e. different projections and coastline compilations). There is strong correlation between Av and $A$ (coefficient of correlation, $R=0.897$; root-meansquare residual, $\mathrm{rms}=68$ ), confirming the visually evident coherence between the two distributions at the continental scale. However, it is important to identify differences at the regional scale. Our first approach examines a field of accumulation residuals between the distributions, and our second approach examines differences in estimates of accumulation for drainage systems.

\section{Based on accumulation residuals}

The difference between the mean values of Av and $A$ (161 and $155 \mathrm{~kg} \mathrm{~m}^{-2} \mathrm{a}^{-1}$, respectively) is $6 \mathrm{~kg} \mathrm{~m}^{-2} \mathrm{a}^{-1}$, and the standard deviation $\mathrm{SD}=70 \mathrm{~kg} \mathrm{~m}^{-2} \mathrm{a}^{-1}$ (Fig. 3c). Residual values are $\leq 1$ SD for 3486 gridpoint locations or approximately $66 \%$ of the sample. The locations with values in this range are widespread throughout the interior of the grounded ice sheet in both East and West Antarctica as well as on large areas of the Ross and Filchner-Ronne Ice Shelves. This part of the residual field substantiates the overall general agreement between the distributions referred to above. Residual values are $\geq 2$ SD for 306 gridpoint locations or approximately $6 \%$ of the sample; most of these locations are in mountainous areas or along relatively narrow zones along either the coast or the grounding line, i.e. where the $A v$ and $A$ values are least reliable.

In the remaining area sampled by 1507 gridpoint locations or approximately $28 \%$ of the sample, there are three regions where concentrations of residual values in the range $75-125 \mathrm{~kg} \mathrm{~m}^{-2} \mathrm{a}^{-1}$ are observed. The concentrations of positive residuals centered at $78^{\circ} \mathrm{S}, 140^{\circ} \mathrm{E}$ and $78^{\circ} \mathrm{S}, 103^{\circ} \mathrm{W}$ are readily explained by our exclusion of data considered to be incompatible with other data for the same region (as mentioned above). The concentration of positive residuals centered at $76.5^{\circ} \mathrm{S}, 13^{\circ} \mathrm{E}$ might be explained by our lack of full information for the region; Vaughan and others (1999) show some data sites in the sector $30^{\circ} \mathrm{W}$ to $7^{\circ} \mathrm{E}$, north of $80^{\circ} \mathrm{S}$, that due to oversight are not included in our field-data compilation. Furthermore, the positive residuals in the three regions could be the result, at least in part, of Vaughan and others (1999) using an independent background field to control the interpolation of field data in areas where these are sparse. The field is partially defined by a hyperbolic function of microwave emissivity (Zwally and Giovinetto, 1995) using a single set of coefficients throughout its application. We believe that the function should be defined using a minimum of two alternate sets of coefficients if it is to reliably aid in the interpolation process over the full range of accumulation observed in Antarctica (Zwally and Giovinetto, 1995).

\section{Based on accumulation estimates for drainage systems}

A comprehensive comparison between the distributions of accumulation presented in Vaughan and others (1999) and in this study at drainage-system scale is beyond the scope of this study, as it would require detailed discussion of the composite error in the two estimates for each drainage system. Nevertheless, an indirect comparison is possible using estimates of accumulation for drainage systems relative to a third compilation (Giovinetto and Bentley, 1985; hereinafter referred to as the 1985 compilation). The first assessment of deviations relative to the 1985 compilation is based on detailed area integration of the rate for the conterminous grounded-ice area of each system reported by Vaughan and others (1999). The second assessment of deviations relative to the 1985 compilation is based on coarse-grid sampling completed by us in the process of collating a multi-

Table 2. Comparison of accumulation estimates (grounded-ice area)

\begin{tabular}{|c|c|c|c|c|c|c|c|c|c|c|}
\hline \multirow[t]{3}{*}{ No. } & \multirow[t]{3}{*}{ Desig. } & \multicolumn{4}{|c|}{ Giovinetto and Bentley (1985) } & \multicolumn{3}{|c|}{ Vaughan and others (1999) } & \multicolumn{2}{|c|}{ Acc. (this study) } \\
\hline & & Def.adj. & Ab. adj. & Acc. (adj.) & Area & Accum. & Accum. ch. & Areach. & Unadj.'85 & Ch.'99 \\
\hline & & $\mathrm{Gta}^{-1}$ & $\mathrm{Gta}^{-1}$ & $\mathrm{Gta}^{-1}$ & $10^{6} \mathrm{~km}^{2}$ & $\mathrm{Gta}^{-1}$ & $\%$ & $\%$ & $\mathrm{Gta}^{-1}$ & $\%$ \\
\hline 1 & $\mathrm{JJ}^{\prime}$ & 3.8 & 0.0 & 74.1 & 0.249 & 92.0 & 24 & 7.1 & 77.9 & 18 \\
\hline 2 & $\mathrm{~J}^{\prime} \mathrm{J}^{\prime \prime}$ & 2.3 & 0.0 & 85.0 & 0.891 & 89.2 & 5 & -0.8 & 87.3 & 2 \\
\hline 3 & $\mathrm{~J}^{\prime \prime} \mathrm{K}$ & 1.9 & 0.0 & 79.8 & 1.668 & 105.6 & 32 & 0.5 & 81.7 & 29 \\
\hline 5 & $\mathrm{~K}^{\prime} \mathrm{A}$ & 8.7 & 0.0 & 25.7 & 0.184 & 32.0 & 25 & 3.3 & 34.4 & -7 \\
\hline 6 & $\mathrm{AA}^{\prime}$ & 6.6 & 0.0 & 81.1 & 0.613 & 75.8 & -7 & -4.4 & 87.7 & -14 \\
\hline 7 & $\mathrm{~A}^{\prime} \mathrm{A}^{\prime \prime}$ & 4.1 & 2.3 & 39.2 & 0.411 & 61.2 & 56 & 3.4 & 45.6 & 34 \\
\hline 8 & $\mathrm{~A}^{\prime \prime} \mathrm{B}$ & 3.5 & 3.4 & 27.1 & 0.222 & 39.6 & 46 & -5.0 & 34.0 & 16 \\
\hline $9-11$ & $\mathrm{BC}$ & 3.5 & 0.0 & 54.8 & 1.280 & 86.8 & 58 & -0.4 & 58.3 & 49 \\
\hline 12 & $\mathrm{CC}^{\prime}$ & 12.6 & 2.1 & 129.6 & 0.725 & 159.5 & 23 & -2.1 & 144.3 & 11 \\
\hline 13 & $\mathrm{C}^{\prime} \mathrm{D}$ & 13.7 & 4.1 & 174.4 & 1.144 & 245.6 & 41 & 2.2 & 192.2 & 28 \\
\hline 14 & $\mathrm{DD}^{\prime}$ & 8.7 & 1.6 & 100.1 & 0.726 & 131.3 & 31 & -5.8 & 110.4 & 19 \\
\hline 16 & $\mathrm{D}^{\prime \prime} \mathrm{E}$ & 0.8 & 0.0 & 19.6 & 0.265 & 25.5 & 30 & -0.9 & 20.4 & 25 \\
\hline 17 & $\mathrm{EE}^{\prime}$ & 2.5 & 0.0 & 89.6 & 1.615 & 102.6 & 14 & -0.3 & 92.1 & 11 \\
\hline 18 & $\mathrm{E}^{\prime} \mathrm{E}^{\prime \prime}$ & 0.0 & 0.0 & 67.6 & 0.497 & 74.5 & 10 & 14.7 & 67.6 & 10 \\
\hline 19 & $\mathrm{E}^{\prime \prime} \mathrm{F}$ & 0.0 & 0.0 & 25.3 & 0.163 & 27.7 & 10 & 33.9 & 25.3 & 9 \\
\hline 20 & $\mathrm{FF}^{\prime}$ & 0.0 & 0.0 & 12.8 & 0.055 & 13.7 & 7 & -11.8 & 12.8 & 7 \\
\hline 21 & $\mathrm{~F}^{\prime} \mathrm{G}$ & 8.3 & 0.0 & 30.0 & 0.142 & 44.1 & 47 & -0.4 & 38.3 & 15 \\
\hline 22 & $\mathrm{GH}$ & 4.7 & 0.0 & 162.2 & 0.411 & 156.4 & -4 & -0.3 & 166.9 & -6 \\
\hline 23 & $\mathrm{HH}^{\prime}$ & 9.6 & 0.0 & 65.4 & 0.082 & 51.6 & -21 & -7.7 & 75.0 & -31 \\
\hline 24 & $\mathrm{H}^{\prime} \mathrm{I}$ & 11.5 & 0.0 & 49.8 & 0.113 & 59.6 & 20 & -9.6 & 61.3 & -3 \\
\hline $1-24$ & (All) & 117.1 & 14.4 & 1468.0 & 11.827 & 1737.5 & 18 & -0.5 & 1599.5 & 9 \\
\hline
\end{tabular}

Notes: No., drainage system number; Def. adj., deflation adjustment; Ab. adj., ablation adjustment; Acc. (adj.), accumulation (adjusted); ch., change. 


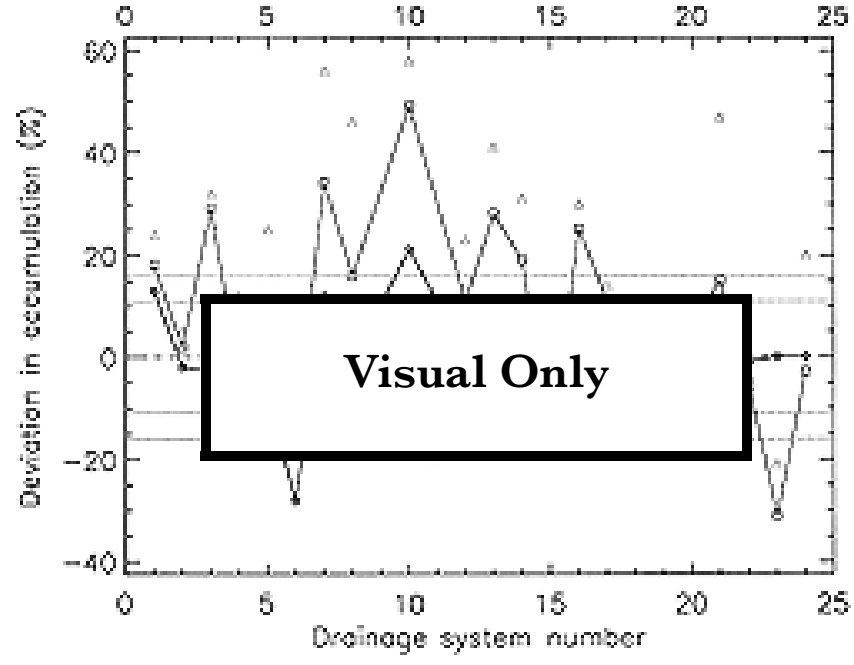

Fig. 4. Deviations in estimates of mean net accumulation at the surface for drainage systems 1-24 (systems 9-11 treated as one; Fig. 1) relative to a preceding distribution (Giovinetto and Bentley, 1985). Deviations listed in Vaughan and others (1999) for the grounded-ice area of each system (red triangles) modified in this study to assess the differences in distribution ( Table 2) are shown by green squares. Deviations indicated in this study for the grounded-ice and ice-shelf areas of each system ( Table 3) are shown by black triangles.

variate $100 \mathrm{~km}$ grid database for the whole area of each system (grounded ice and ice shelf).

In the comparison with the 1985 compilation, Vaughan and others (1999) listed results for 22 systems (systems 9-11 treated as one) (Table 2; Fig. 4). The estimates listed for the 1985 compilation correspond to values reduced by the implementation of deflation and ablation adjustments (described above). As the comparison included changes of area, we summarize the accumulation changes using bulk estimates (mean rate times the area), which were reported to be between (-)21\% and 58\% (Vaughan and others, 1999). The composite error estimate for each of the two compilations (i.e. $\pm 5 \%$ (Vaughan and others, 1999 ) and $\pm 10 \%$ (Giovinetto and Bentley, 1985)) suggest that differences $\geq \pm 11 \%$ identify systems for which the indicated changes are larger than the sum of the errors (treated as standard errors). This is a cursory assessment of "uncertainty" to serve as a guideline in identifying outstanding differences, and not a substitute for an assessment of errors to determine statistical significance. Its use identifies 16 of the 22 systems.

However, we are interested in assessing differences between the distributions as shown on maps rather than differences involving adjustments applied after area integration. For this purpose we modify the comparison reported by Vaughan and others (1999) by removing the deflation and ablation adjustments listed in the 1985 compilation, all of which apply only to the coastal area of the conterminous grounded ice. Thus modified, the overall change in accumulation for the conterminous grounded ice sheet is reduced to 9\% from the 18\% reported in Vaughan and others (1999). On this basis, the comparison indicates deviations of accumulation between (-) $31 \%$ and $49 \%$ (a range of 80 percentile), with deviations $\geq \pm 11 \%$ listed for 14 systems. The deviations are due, in part, to new estimates of area for each system. The change in the estimate of total grounded-ice area relative to the 1985 compilation is small $(-0.5 \%)$, but

Table 3. Comparison of accumulation estimates (whole area)

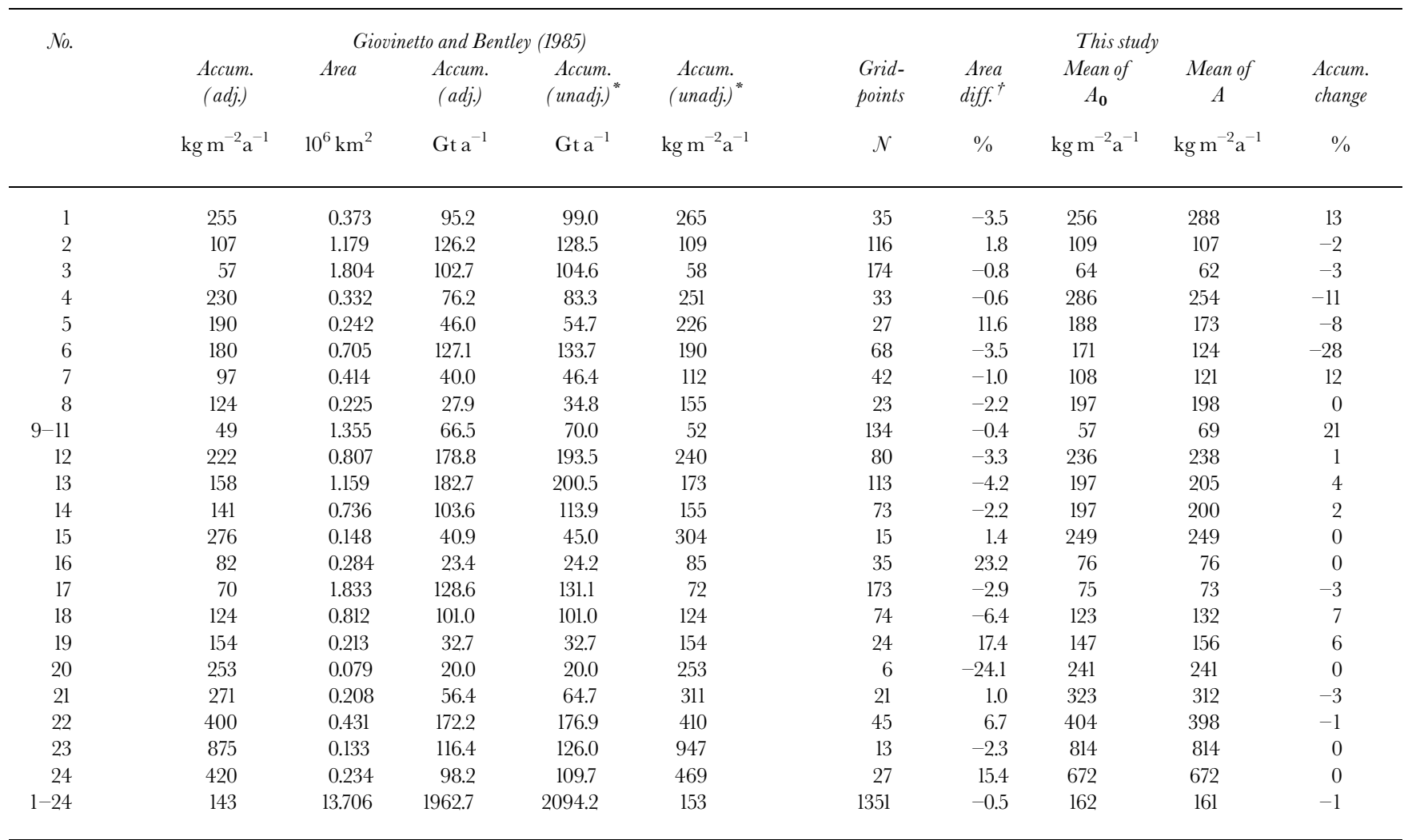

Notes: No., drainage system number; Def. adj., deflation adjustment; Ab. adj., ablation adjustment; acc. (adj.), accumulation (adjusted); ch., change.

* Removal of deflation and ablation adjustments (listed in Table 1).

$\dagger$ Difference in area indicated by grid sampling.

$\ddagger$ Different mean accumulation values obtained by area integration (153) and grid sampling (162). 
the changes indicated for particular systems are between ($12 \%$ and $34 \%$, with changes between $(-) 10 \%$ and $7 \%$ listed for 18 systems. These changes include probable errors in the estimate of area for each system as listed in the 1985 compilation and, more importantly, changes in the delineation of drainage divides using proprietary software applied in the analysis of updated surface topography based on European remote-sensing satellite (ERS-1) radar altimeter data (Vaughan and others, 1999).

We summarize the results of a comparison between the distributions shown in Figure 2 and in the 1985 compilation, in this case for the whole area of each system, and treating systems 9-11 as one to make it easier to contrast the results (Table 3). We did not revise the delineation of drainage divides as shown in the 1985 compilation, and produced accumulation datasets based on $100 \mathrm{~km}$ grid sampling of the two distributions. The gridpoint locations $(N=1351)$ match corresponding gridpoint locations in the $50 \mathrm{~km}$ grid described above. The $100 \mathrm{~km}$ grid sampling of the whole area of each of the 24 systems in the 1985 compilation indicates a mean accumulation of $162 \mathrm{~kg} \mathrm{~m}^{-2} \mathrm{a}^{-1}$ (Table 3) that is $6 \%$ larger than the mean obtained by detailed area integration of the rate $\left(153 \mathrm{~kg} \mathrm{~m}^{-2} \mathrm{a}^{-1}\right)$, and which is closer to the mean obtained by $50 \mathrm{~km}$ grid sampling (159 $\mathrm{kg} \mathrm{m}^{-2} \mathrm{a}^{-1}$; Table 1). The combined uncertainty applicable to our comparison is assessed at $\pm 16 \%$ on the basis of the composite error of $\pm 10 \%$ (Giovinetto and Bentley, 1985) allocated to each of the compilations, and an error of $\pm 6 \%$ also allocated to each compilation because the estimates are produced by coarse-grid sampling. Our comparison indicated deviations in accumulation estimates between $(-) 27 \%$ and $21 \%$ (a range of 48 percentile), with changes $\geq \pm 16 \%$ listed for only two systems; for perspective, it may be noted that even using the error assessed for the preceding comparison $( \pm 11 \%)$ would have identified five systems, i.e. also a relatively small number.

Coarse-grid sampling produces a first-approximation estimate of area for each system (the nominal area allocated to each gridpoint is $10000 \mathrm{~km}^{2}$ adjusted for projection deformation using the area scale factor). Changes in area relative to those listed in the 1985 compilation for systems $20(-24 \%)$ and $16(23 \%)$ are larger than the difference that would be expected from coarse-grid sampling, although the area of those systems is relatively small, and a few gridpoints just outside or inside the divide would introduce a large difference. Nevertheless, the differences might indicate measurement errors that can be traced back to an earlier compilation (Giovinetto, 1964b). The differences indicated for the other 20 systems are between $(-) 6 \%$ and $17 \%$. We intend to revise the measurements of area for each system following a new delineation of drainage divides based on ERS-1 radar altimeter data, but at present we are not fully satisfied with results obtained by applying hydrological modeling tools.

\section{SUMMARY AND GONGLUSIONS}

The clear contrast between the findings of the two separate comparisons of the distributions produced by Vaughan and others (1999), and in this study, with the 1985 compilation is defined by three aspects. The first, already noted, is the number of systems showing accumulation changes that are larger than the combined uncertainty in each comparison (14 systems in the comparison by Vaughan and others
(1999) as modified in this study, vs two systems in our comparison). The second aspect is the difference in the range of the changes indicated by each comparison (a range of 80 percentile between $(-) 31 \%$ and $49 \%$ in the comparison of Vaughan and others (1999) as modified in this study, vs a range of 48 percentile between (-)27\% and $21 \%$ in our comparison). Only a small part of the difference in the range could be explained by changes in area due to the new delineation of drainage divides as shown in Vaughan and others (1999).

The third aspect is the disparity between the changes indicated by each comparison for particular systems, and which range from 1 percentile for system 5 , to 28 percentile for systems 9-11. Part of the disparity noted for a particular system is explained by the fact that the indicated changes are, one for the grounded-ice area, and the other to the whole area, of each system. In this context, it should be noted that the disparity is relatively small for the four systems with the largest ice-shelf areas (1, 2, 17 and 18; respectively, the western and central Filchner-Ronne Ice Shelf systems and the western and central Ross Ice Shelf systems). Nevertheless, this physiographic difference introduces a new component of uncertainty, which we assume is of the same magnitude as the other components ( say $\pm 10 \%$ ). Thus, we assess the overall uncertainty applicable to the discussion of disparities as the sum of those pertaining to each comparison (i.e. $\pm 11 \%$ and $\pm 16 \%$ ) plus $\pm 10 \%$, and suggest that any disparity of 22 percentile or larger identifies systems where the differences between the distributions are substantial. This is noted for six systems (3, 7, 9-11, 13, 16 and 23). Some of these disparities may be explained, in part, by aspects already discussed (e.g. systems 3, 16 and 23 include all or relatively large parts of the regions showing concentration of residual values in a particular range (i.e. centered, respectively, at approximately $76.5^{\circ} \mathrm{S}, 13^{\circ} \mathrm{E} ; 78^{\circ} \mathrm{S}, 140^{\circ} \mathrm{E}$; and $\left.78^{\circ} \mathrm{S}, 103^{\circ} \mathrm{W}\right)$ ). Collectively, the six systems noted for large disparities comprise (relative to the estimated values listed in the 1985 compilation for the whole area including ice shelves) approximately $4 / 10$ of the ice-sheet area and 3/10 of the accumulation. The implicit differences of accumulation indicated by the two distributions for all or part of the area of each of those systems are relevant to studies such as mass-budget estimates and the validation of model output derived from atmospheric numerical analyses.

\section{ACKNOWLEDGEMENTS}

The authors acknowledge the contributions of D. Vaughan and C. Conrad who provided sets and subsets for the databases, and M. Beckley and J. Saba for computation and graphics.

\section{REFERENGES}

Bentley, C. R. and M. B. Giovinetto. 1991. Mass balance of Antarctica and sea level change. InWeller, G., C. L. Wilson and B. A. B. Severin, eds. International Conference on the Role of the Polar Regions in Global Change: proceedings of a conference held June 11-15, 1990 at the University of Alask a Fairbanks. Vol. II. Fairbanks, AK, University of Alaska. Geophysical Institute/Center for Global Change and Arctic System Research, 481-488.

Bentley, C. R. and J. M. Wahr. 1998. Satellite gravity and the mass balance of the Antarctic ice sheet. F. Glaciol., 44(147), 207-213.

Bromwich, D. H., R. I. Cullather and M. L. Van Woert. 1998. Antarctic precipitation and its contribution to the global sea-level budget. Ann. Glaciol., 27, 220-226.

Budd, W. F. and R. C. Warner. 1996. A computer scheme for rapid calculations of balance-flux distributions. Ann. Glaciol., 23, 21-27.

Budd, W. F., B. Coutts and R. C. Warner. 1998. Modelling the Antarctic and 
Northern Hemisphere ice-sheet changes with global climate through the glacial cycle. Ann. Glaciol., 27, 153-160.

Casassa, G., H. H. Brecher, C. Cárdenas and A. Rivera. 1998. Mass balance of the Antarctic ice sheet at Patriot Hills. Ann. Glaciol., 27, 130-134.

Chorlton, J. C. and H. Lister. 1970. Snow accumulation over Antarctica. International Association of Scientific Hydrology Publication 86 (Symposium at Hanover 1968 - Antarctic Glaciological Exploration (ISAGE)), 254-263.

Comiso, J. C. 1994. Surface temperatures in the polar regions from Nimbus 7 temperature humidity infrared radiometer. 7. Geophys. Res., 99(C3), 5181-5200.

Comiso, J. C. 2000. Variability and trends in Antarctic surface temperatures from in situ and satellite infrared measurements. F. Climate, 13(10), 1674-1696.

Conrad, C. P. and B. H. Hager. 1995. The elastic response of the Earth to interannual variations in Antarctic precipitation. Geophys. Res. Lett., 22(23), 3183-3186.

Ferrigno, J. G. and 7 others. 1996. Antarctica. Scale 1:5000 000. U.S. Geol. Surv. Misc. Field Invest. Map, I-2560.

Genthon, C. and A. Braun. 1995. ECMWF analyses and predictions of the surface climate of Greenland and Antarctica. 7. Climate, 8(10), 2324-2332.

Giovinetto, M. B. 1964a. Distribution of diagenetic snow facies in Antarctica and in Greenland. Arctic, 17 (1), 32-40.

Giovinetto, M. B. 1964b. The drainage systems of Antarctica: accumulation. In Mellor, M., ed. Antarctic snow and ice studies. Washington, DC, American Geophysical Union, 127-155. (Antarctic Research Series 2.)

Giovinetto, M. B. and C. R. Bentley. 1985. Surface balance in ice drainage systems of Antarctica. Antarct. F. U.S., 20 (4), 6-13.

Giovinetto, M. B. and C. Bull. 1987. Summary and analyses of surface mass balance compilations for Antarctica, 1960-1985. Byrd Polar Res. Cent. Rep. 1.

Giovinetto, M. B., C. R. Bentley and C. B. B. Bull. 1989. Choosing between some incompatible regional surface-mass-balance data sets in Antarctica. Antarct. 7. U.S., 24(1), 7-13.

Giovinetto, M. B., N. M. Waters and C. R. Bentley. 1990. Dependence of Antarctic surface mass balance on temperature, elevation, and distance to open ocean. 7. Geophys. Res., 95(D4), 3517-3531.

Goodwin, I. D. 1990. Snow accumulation and surface topography in the katabatic zone of eastern Wilkes Land, Antarctica. Antarct. Sci., 2(3), 235-242.

Goodwin, I. D., M. Higham, I. Allison and R. Jiawen. 1994. Accumulation variation in eastern Kemp Land, Antarctica. Ann. Glaciol., 20, 202-206.

Graf, W. and 6 others. 1994. Snow-accumulation rates and isotopic content $\left({ }^{2} \mathrm{H}\right.$, $\left.{ }^{3} \mathrm{H}\right)$ of near-surface firn from the Filchner-Ronne Ice Shelf, Antarctica. Ann. Glaciol., 20, 121-128.

Higham, M., M. Craven, A. Ruddell and I. Allison. 1997. Snow-accumulation distribution in the interior of the Lambert Glacier basin, Antarctica. Ann. Glaciol., 25, 412-417.

Isaksson, E. and W. Karlén. 1994. High resolution climatic information from short firn cores, western Dronning Maud Land, Antarctica. Climatic Change, 26(4), 421-434.

Jacobs, S. S., H. H. Hellmer, C. S. M. Doake, A. Jenkins and R. M. Frolich. 1992. Melting of ice shelves and the mass balance of Antarctica. F. Glaciol., $38(130), 375-387$.

James, T. S. and E. R. Ivins. 1997. Global geodetic signatures of the Antarctic ice sheet. f. Geophys. Res., $102(\mathrm{B1}), 605-633$.

Jenkins, A. and C. S. M. Doake. 1991. Ice-ocean interaction on Ronne Ice Shelf, Antarctica. 7. Geophys. Res., 96 (Cl), 791-813.
Kobayashi, S. 1978. Snow transport by katabatic winds in Mizuho Camp area, East Antarctica. 7. Meteorol. Soc. Jpn, 56(2), 130-139.

Melvold, K., J. O. Hagen, J. F. Pinglot and N. Gundestrup. 1998. Large spatial variation in accumulation rate in Jutulstraumen ice stream, Dronning Maud Land, Antarctica. Ann. Glaciol., 27, 231-238.

Morgan, V. I., I. D. Goodwin, D. M. Etheridge and C.W. Wookey. 1991. Evidence from Antarctic ice cores for recent increases in snow accumulation. Nature, 354(6348), 58-60.

Mosley-Thompson, E. and 6 others. 1995. Recent increase in South Pole snow accumulation. Ann. Glaciol., 21, 131-138.

Ohmura, A., M. Wild and L. Bengtsson. 1996a. A possible change in mass balance of Greenland and Antarctic ice sheets in the coming century. $\mathcal{F}$. Climate, 9(9), 2124-2135.

Ohmura, A., M. Wild and L. Bengtsson. 1996b. Present and future mass balance of the ice sheets simulated with GCM. Ann. Glaciol., 23, 187-193.

Parish, T. R. and D. H. Bromwich. 1991. Continental-scale simulation of the Antarctic katabatic wind regime. F. Climate, 4(2), 135-146.

Pattyn, F. 1996. Numerical modelling of a fast-flowing outlet glacier: experiments with different basal conditions. Ann. Glaciol., 23, 237-246.

Pinther, M., ed. 1975. Map of the Arctic region. (Scale 1:5M.) New York, American Geographical Society. (The World Sheet 14.)

Richardson, C., E. Aarholt, S-E. Hamran, P. Holmlund and E. Isaksson. 1997. Spatial distribution of snow in western Dronning Maud Land, East Antarctica, mapped by a ground-based snow radar. 7. Geophys. Res., 102(B9), 20,343-20,353.

Rignot, E. 1998. Radar interferometry detection of hinge-line migration on Rutford Ice Stream and Carlson Inlet, Antarctica. Ann. Glaciol., 27, 25-32.

Takahashi, S. and O. Watanabe. 1997. Snow accumulation. In Antarctica: east Queen Maud Land/Enderby Land glaciologicalfolio. Tokyo, National Institute of Polar Research, Sheet 3.

Van den Broeke, M. R. and R. Bintanja. 1995. The interaction of katabatic winds and the formation of blue-ice areas in East Antarctica. F. Glaciol., 41 (138), 395-407.

Van den Broeke, M. R., R. S.W. van de Wal and M. Wild. 1997. Representation of Antarctic katabatic winds in a high resolution GCM and a note on their climate sensitivity. 7. Climate, 10(12), 3111-3130.

Van den Broeke, M. R. and 6 others. 1999. Climate variables along a traverse line in Dronning Maud Land, East Antarctica. 7. Glaciol., 45(150), 295-302.

Vaughan, D. G., J. L. Bamber, M. B. Giovinetto, J. Russell and A. P. R. Cooper. 1999. Reassessment of net surface mass balance in Antarctica. 7. Climate, $12(4), 933-946$.

Venteris, E. R. and I. M. Whillans. 1998. Variability of accumulation rate in the catchments of Ice Streams B, C, D and E, Antarctica. Ann. Glaciol., 27, 227-230.

Whillans, I. M. and R. A. Bindschadler. 1988. Mass balance of Ice Stream B, West Antarctica. Ann. Glaciol., 11, 187-193.

Williams, R. S., Jr, J. G. Ferrigno, C. Swithinbank, B. K. Lucchitta and B. A. Seekins. 1995. Coastal-change and glaciological maps of Antarctica. Ann. Glaciol., 21, 284-290.

Zwally, H. J. and S. Fiegles. 1994. Extent and duration of Antarctic surface melt. F. Glaciol., 40(136), 463-476.

Zwally, H. J. and M. B. Giovinetto. 1995. Accumulation in Antarctica and Greenland derived from passive-microwave data: a comparison with contoured compilations. Ann. Glaciol., 21, 123-130. 